\title{
Inequalities in the reproductive health knowledge and practices of unmarried adolescent boys and girls in Eastern India: a cross-sectional survey
}

Shantanu Sharma ( $\nabla$ shantanusharma145@gmail.com )

MAMTA Health Institute for Mother and Child https://orcid.org/0000-0002-5064-4782

Sonali Maheshwari

MAMTA HIMC: MAMTA Health Institute for Mother and Child

Jitesh Kuwatada

MAMTA HIMC: MAMTA Health Institute for Mother and Child

Chandra Shekhar

MAMTA HIMC: MAMTA Health Institute for Mother and Child

\section{Sunil Mehra}

MAMTA HIMC: MAMTA Health Institute for Mother and Child

\section{Research}

Keywords: Contraceptives, Community-based, Health education, HIV, Menstrual hygiene, Menstruation disturbance, Self-Efficacy, Socioeconomic factors

Posted Date: April 5th, 2021

DOl: https://doi.org/10.21203/rs.3.rs-349512/v1

License: (c) (1) This work is licensed under a Creative Commons Attribution 4.0 International License. Read Full License 


\section{Abstract}

Background: Adolescents lack adequate knowledge, self-efficacy, and access to sexual and reproductive health services; thereby, predisposing them to sexual violence, sexually transmitted infections, early marriage, and high fertility rates. Socio-economic inequalities fuel such problems, but we have limited evidence from some of the least developed states of Eastern India. Therefore, we aimed to assess the inequalities in the reproductive health knowledge and practices of unmarried adolescents (10-19 years) from marginalized populations in one district each from the state of Bihar and Assam in India.

Methods: It was a community-based cross-sectional study with a quantitative research methodology. In our study, we captured data on five domains related to reproductive health, including knowledge about HIV/AIDS, and contraceptives, awareness and perceptions related to right age at marriage, general selfefficacy, menstrual hygiene practices among girls, and access to health services for reproductive health problems; besides socio-demographic details. We performed a 2-step cluster analysis to gain insights into the patterns of reproductive health knowledge and self-efficacy among unmarried adolescent boys and girls, separately. Multinomial logistic regression analysis was employed to identify the predictors associated with the cluster membership determined through cluster analysis.

Results: A total of 811 boys and 826 girls participated in the study. Three-clusters were identified for boys and girls in the analysis, varying from high to low knowledge and self-efficacy for boys, and high to low knowledge with constant low self-efficacy in all the three clusters for girls. Higher educational status and increasing age were positively associated with the high knowledge clusters among boys and girls. Additionally, marginalized social class and working status were associated with higher knowledge cluster in girls.

Conclusions: We emphasize on the need of comprehensive (covering a broad range of reproductive health issues, such as child marriage, contraceptives, HIV/AIDS, menstrual hygiene, etc.), contextualized (relevant for adolescents in the least developed states like Bihar), and customized (tailored for different cultures and religions through appropriate means) sexual and reproductive health education for adolescents.

\section{Background}

Adolescents make up $16 \%$ of the world's population, i.e., 1.2 billion people [1]. Unfortunately, 1.3 million adolescents die each year from preventable causes, such as violence, HIV, accidents, pneumonia, and suicide [2]. Adolescents are at risk of sexual violence, reproductive tract infections (RTI), such as HIV/AIDS, and injuries as they experiment and explore sexual identity, sexual practices, and high-risk behaviors [3]. They have the highest unmet needs of contraception, i.e., $23 \%$, compared to $15 \%$ among women aged $30-34$. Only $15 \%$ of married or in-union adolescent girls use modern contraceptives, resulting in a high fertility rate [4]. Furthermore, the situation is grave in low- and middle-income countries where 
not only adolescents have knowledge gaps, misconceptions, and limited access to services, but their parents or teachers themselves are ill-informed and hesitant to discuss reproductive health issues $[5,6]$.

Factors contributing to increased fertility and poor reproductive health outcomes among adolescents include low educational attainment, decision-making power, economic independence, and access to health services, and harmful traditional norms [7]. Furthermore, lack of knowledge and access to sexual and reproductive health services predispose adolescents to unwanted pregnancies, unsafe abortion, and sexually transmitted infections [8]. Socio-economic inequalities have also been identified as an important risk factor for adolescent's reproductive health problems [7]. There is an emerging focus on addressing these gaps and increased investments in adolescent health. The Lancet commission on adolescent health and global strategy calls for comprehensive and integrated investments and scale-up of the evidence-based actions for adolescents in low resource settings for high social and economic returns [9, 10].

Adolescents, constituting a quarter of India's population, face numerous reproductive and sexual health problems, such as early marriage, teenage pregnancies, vulnerability to sexually transmitted infections, and increased maternal mortality $[11,12]$. India has the highest absolute number of child brides in the world, and an estimated 11.8 million teenage pregnancies in a year $[13,14]$. Launched in 2014, the National Adolescent Health Program in India is yet to make an impactful change in the adolescent's health $[12,15]$. The burgeoning demand for adolescents' development and improved adolescent-friendly health services has created the need for comprehensive research and evidence generation. Assessment of the inequalities in disease burden and access to reproductive health services and the effectiveness of the community-based interventions are among the research priorities identified by the world health organization for adolescent health $[16,17]$.

There is empirical evidence of the effect of social inequalities in health and healthcare in India. However, we lack sufficient evidence on how social inequalities are related to the reproductive health knowledge and practices of adolescents in India [18]. Given the need to fill in the research gap and draw the basis for comparing the outcomes of an intervention, we sought to explore the reproductive health knowledge and practices among adolescents. Our study is a part of the baseline evaluation of a community intervention aimed at improving the maternal and adolescent reproductive health and enhanced access to services. The baseline evaluation, conducted in 2017, assessed the knowledge, attitude, and practices of pregnant and lactating women and adolescents regarding reproductive health.

In the present study, we aimed to assess the inequalities in the reproductive health knowledge and practices of adolescents (10-19 years) in one district each from the state of Bihar and Assam in India.

\section{Methods}

\subsection{Study design and setting}


The present study is a community-based cross-sectional study conducted in the two states of India, namely Bihar and Assam. Munger and Darang districts were selected as part of the intervention geographies in Bihar and Assam, respectively, and hence, the baseline study was administered in these two districts (Figure 1). The survey was conducted in both urban and rural areas. The urban area was selected from Munger district only, and rural areas were selected from both Munger and Darang districts (due to intervention priority).

\subsection{Sample size}

Considering the $50.0 \%$ prevalence of knowledge of reproductive health among adolescents [19], $95 \%$ confidence level, $5 \%$ absolute error, design effect of 1.2 , and $5 \%$ drop rate, the sample size was calculated at 504. This sample of adolescents was interviewed in each of the three study sites ( 2 rural and 1 urban sites). So, the minimum number of girls or boys required to detect a statistical difference in the reproductive health knowledge and self-efficacy were 504 .

\subsection{Sampling and sample selection}

First of all, the urban wards and Gram Panchayats (local administrative units in villages) were listed down for the districts. Then, the required number of primary sampling units were selected randomly using probability proportional to size. The selected urban wards and Gram Panchayats were the primary sampling units (PSU) for the study. The selection of PSU was carried out on the basis of probability proportional to size (PPS). A total of 45 urban wards and 5 Gram Panchayats ( 3 from Munger and 2 from Darang) were selected. For the selection of households, systematic random sampling was used, following right-hand thumb rule. From each selected household, one eligible and willing respondent was chosen for the interview. The eligibility criteria for inclusion of the study participant in the sampling frame included unmarried adolescents (girls and boys) between 10-19 years and residing in the study area for at least the last one year. The study participants were approached only once for the survey. In case the participants were not found at home, the second visit was not done to that house, and a house adjacent to that one was selected.

\subsection{Ethical consideration}

Utmost care was ensured by adhering to the ethical guidelines and maintaining confidentiality as the survey aimed to gather information about reproductive health issues among adolescents. MAMTA Institutional Review Board (MIRB) granted ethical clearance for the study. We did not have issues while obtaining the consents as MAMTA has been working for the last 10 years in the states and has a good rapport with the community stakeholders and local government functionaries. Besides, due consent of parents and assent of adolescents were taken before the start of each interview.

\subsection{Study tool}

In our study, we captured data on five domains related to reproductive health, including knowledge about HIV/AIDS, and contraceptives, awareness and perceptions related to right age at marriage, general self- 
efficacy, menstrual hygiene practices among girls, and access to health services for reproductive health problems; besides socio-demographic details. In the socio-demographic section, we collected information on residence (rural/urban), age, gender (male/female), years of schooling, religion (Hindu, Muslim, and Others that included Sikhs, Christians, and Jains), occupation status (working outside home yes/no), below the poverty line status (had below poverty line card), and social-cultural group or caste (scheduled caste/tribe, other special class, or general).

We asked for the awareness and source of information about nine contraceptives (male and female condoms, Copper T, oral contraceptive pills, depo-medroxyprogesterone acetate injection, male and female sterilization, rhythm method, and emergency pills). The awareness about every method of contraceptive was scored 1 for 'yes,' and 0 for 'no.' All the scores of the 9 questions about contraceptive awareness were summed-up to generate the final score with the range of 0-9, which was further divided into three categories as low (0-3), medium (4-6), and high (7-9) level awareness. Cronbach's alpha value was used to represent the internal consistency of this item, the value of which was 0.77 . Furthermore, information about the source of contraceptives was also sought from each of the eligible respondents.

We asked adolescents if they heard of HIV and AIDS and assessed knowledge about different sources of HIV infection. In this case, the seven different questions related to the correct knowledge about sources of HIV infection were asked, and their responses were 1 for 'yes' and 0 for 'no.' The final score generated after summing up the scores of all the seven questions was grouped into three categories, namely low (02), medium (3-4), and high (5-7) level knowledge. Cronbach's alpha value for the internal consistency of the scale was 0.6. The awareness and perceptions related to age at marriage had the following questions: What is the legal age at marriage for boys and girls; When do adolescents want to get married; At what age do boys and girls get married in their societies?" and "Are you aware of any government scheme or policy to stop child marriage?".

We used a 4-point Likert scale for measuring general self-efficacy with responses varying from completely agree to completely disagree with the statements. The Schwarzer's General Self-efficacy scale (GSES) was adopted with some modifications [20]. After aligning the scores of each of the 12 statements of the self-efficacy scale in a positive direction, we summed up the responses with values ranging between 12 (lowest self-efficacy) and 48 (highest self-efficacy). These scores were again grouped to give three groups, namely low (12-31), moderate (32-39), and high (40-48) self-efficacy. Cronbach's alpha value of this scale was 0.89 .

Girls who had menarche were asked about the age at menarche and their practices for menstrual hygiene management (kind of sanitary product used and disposal technique of the used sanitary product). Furthermore, girls were asked of problems during menstrual cycles, such as excessive bleeding during periods, irregular periods, painful periods, pain in the lower abdomen, and missed periods. Presence of a toilet at home was also questioned.

Lastly, adolescents were asked about any reproductive tract related infections or diseases in the past 12months and symptoms suggestive of the reproductive tract or sexually transmitted infections in the last 
3-months. Adolescents were asked about the following symptoms suggestive of the RTI: pain during micturition or burning micturition, foul-smelling discharge from vagina/penis, ulcers in groin or penis, or vulva, pain in testis, bleeding between periods, and pain in groin during intercourse. In addition, we sought information about the access to services for routine health problems in the past 6 -months and for the reproductive tract symptoms they had in the past 3-months.

\subsection{Statistical analysis}

Data were expressed as frequency (percentage) for categorical variables. Radar chart was used to express the prevalence of the various sources of information about contraceptives among boys and girls. We performed a 2-step cluster analysis to gain insights into the patterns of reproductive health knowledge and self-efficacy among adolescents. Five questions were included for clustering, namely, knew about boy's or girl's legal at marriage, heard of HIV/AIDS, self-efficacy, and contraceptive knowledge. Separate cluster analysis was performed for boys and girls as the knowledge and selfefficacy might differ between the two genders. We included only the factors related to knowledge and self-efficacy in the factor analysis because of a lack of responses from all the individuals for the questions related to practice domain. The best clustering solution was ascertained based on the lowest number of clusters and the corresponding fit using Schwarz's Bayesian Information Criterion (BIC) method. We repeated the clustering procedure at least 10 times to assess the stability and reliability of the cluster analysis. The Silhouette Index (SI) was referred to assess the cluster quality.

Multinomial logistic regression analysis was employed to identify the predictors associated with the cluster membership determined through cluster analysis. The dependent variable for the logistic analysis was the type of the cluster obtained from the 2-step cluster analysis, and independent variables were the socio-demographic characteristics. First of all, the individual effect of each of the independent variables on the dependent variable was seen using an unadjusted odds ratio. Later, all the independent variables were included in the final model for the adjusted effect. All the analyses were conducted in SPSS version 25.0 (IBM Corp., Armonk, N.Y., USA).

\section{Results}

As shown in Table 1, more than two-thirds of the study participants were Hindus, followed by Muslims. The number of girls working outside their homes was more than twice the number of boys. Nearly twothirds of boys and more than three-fourths of girls had not heard of AIDS (Table 2). Similarly, more than two-thirds of both girls and boys had not heard of HIV. Only $37 \%$ of boys and $28 \%$ of girls had high selfefficacy scores. General health problems in the last 6 -months were present among $18 \%$ and $34 \%$ of boys and girls, respectively. Around $23 \%$ of girls reported symptoms suggestive of RTI in the past 3-months compared to $9 \%$ of boys.

Out of 811 boys, 330 (37\%) had ever heard about any contraceptives. Similarly, 237 out of $826(28.7 \%)$ girls had ever heard of any contraceptives (Contraceptive-wise awareness is provided in the supplementary file). Sterilization (male and female) was known to around $28 \%$ of adolescent boys and 
condoms and pills to $16-17 \%$ of boys. On the other hand, girls mostly knew of female sterilization (21\%) and oral pills (15\%). Advertisements and friends were the most common sources of information for contraceptives among boys and girls, as shown in Figure 2. However, the source of information for a large percentage of boys (20\%) was traditional healers or quacks for contraceptives compared to girls $(2 \%)$. Around $18-19 \%$ of boys and girls perceived that early marriage of boys was happening in their areas. More than half of the adolescent girls and boys said that they were married off early (by more than 2 years) at age than they actually wanted to marry due to societal pressure.

A nearly equal percentage of girls were using cloths (48\%) or sanitary napkins (43\%) in the early age group (10-14 years), as shown in Table 3. Similarly, in the late adolescent group, an equal percentage of girls used clothes (41\%) or sanitary napkins (45\%). Around two-thirds of girls in the early adolescent group and $76 \%$ of girls in the late adolescent group reported having problems during menses, such as pain in the lower abdomen, excessive bleeding, irregular periods, missed periods, and painful periods (cramps).

The three-clusters identified in the analysis for boys were high knowledge and self-efficacy (31.8\%), medium knowledge and self-efficacy (37.1\%) and low knowledge and self-efficacy (31.1\%), as shown in Table 4a. The ratio of the sizes of the largest and smallest cluster was 1.19, and the SI was 0.6 (good quality). In the high knowledge and self-efficacy cluster, most of the adolescents knew about the legal age at marriage of boys and girls and heard of AIDS and HIV, $50 \%$ had high-level self-efficacy scores, and $84 \%$ had low contraceptive knowledge scores. On the other hand, in the low knowledge and self-efficacy cluster, most of the adolescents did not know of the legal age at marriage of girls and boys, had not heard of HIV/AIDS, had low contraceptive knowledge scores with over $50 \%$ having low self-efficacy scores.

Similarly, the three clusters identified in the analysis for girls were high knowledge and low self-efficacy (31.8\%), medium knowledge and low self-efficacy (46.9\%), and low knowledge and low self-efficacy (21.3\%), as shown in Table 4b. The ratio of the largest and smallest cluster was 2.2, and the SI index was 0.5 (fair quality). In the high knowledge and low self-efficacy cluster, most of the girls knew of the legal age of marriage of girls and heard about AIDS, more than two-thirds of girls knew of the legal age of marriage of boys and heard of HIV, $80 \%$ had low contraceptive knowledge scores and $41.1 \%$ had low selfefficacy scores. In the low knowledge and self-efficacy cluster, most of the girls did not know of the legal age of marriage of boys or girls, had not heard of AIDS or HIV, $97 \%$ had low contraceptive knowledge scores and $62 \%$ had low self-efficacy scores.

Knowledge about the legal age at marriage of boys and girls had the highest predictor importance among boys (Figure 3a) and knowledge about the legal age of marriage of girls and heard about AIDS had the highest predictor importance among girls (Figure $3 b$ ). Adolescent boys who were illiterate or literate up to the primary level had a $99 \%$ decreased chance than the most educated ones, and early adolescents had a nearly $75 \%$ decreased chance than the 15-19 years' age group of being in the high knowledge and selfefficacy cluster compared to the low knowledge and self-efficacy cluster (Table 5a). Similarly, adolescent 
girls who belonged to scheduled caste or tribe classes had 3.2 times higher odds and those who were working had 2.5 times higher odds of being in the high knowledge cluster compared to their counterparts (Table 5b).

\section{Discussion}

We found that most adolescent boys and girls had a low level of awareness about contraceptives and HIV/AIDS. However, most adolescents knew about legal age at marriage for boys and girls in two selected districts. Furthermore, $63 \%$ of girls and $72 \%$ of boys had low to average general self-efficacy scores. We found three clusters of reproductive health knowledge and self-efficacy among boys and girls. Adolescent girls and boys with the high education status, and in the late age group had higher odds of having higher reproductive health knowledge and self-efficacy than their respective counterparts. Additionally, working girls and girls from the scheduled caste or tribes had higher odds of having higher reproductive health knowledge than their respective counterparts.

Our study reported that nearly $90 \%$ of boys and girls had low awareness levels about contraceptives (knew either one or two of the contraceptives or none). Most commonly, sterilization, male condoms, and pills were known to adolescents compared to other contraceptives. In addition, only $37 \%$ of boys and $28 \%$ of girls had ever heard of any contraceptive. These results are comparatively lower than that of another study conducted among school-going adolescents in Maharashtra (a state in central India) [21]. This study reported that $50.3 \%$ of students had heard about condom, $23 \%$ about oral contraceptives, and $10 \%$ knew about emergency contraceptives. Two conditions may explain such incongruent results; first, nearly 20-24\% of adolescents in our study were either illiterate or educated up to primary standard, and second, the sample size in our study was quite large compared to the other study $(n=375)$. On the contrary, the source of information for contraceptives was social media/friends in our study, similar to other studies [22]. It is crucial to note that the knowledge about contraceptives during adolescence may influence their use in adulthood, providing the basic information adolescents have, and potentially build upon, throughout life [23].

Inconsistent with most studies, we found that only $25-35 \%$ of adolescent boys and $20-24 \%$ of girls ever heard of HIV and AIDS [24-26]. We argue that other studies that found a higher prevalence of awareness about HIV/AIDS among adolescents were school-based and conducted in urban areas. The plausible justification for such variations in awareness levels in studies could be the stigma attached to HIV/AIDS that may prevent adolescents from talking about it openly [27]. In the NFHS-4, it was revealed that Bihar had one of the least proportion of people in India who heard about HIV or AIDS, and the awareness was further lower among people from rural areas, marginalized and younger age groups [28]. There are mixed findings pertaining to the knowledge prevalence of legal age at marriage among adolescents varying from $40 \%$ to $90 \%$ [29-32]. In our study, more than two-thirds of adolescents knew legal age at marriage. Child marriage is a social problem in India that undermines a girl's right to autonomy and to live a life free from violence. Also, child marriage has been linked to poor reproductive health outcomes, such as high fertility and unwanted and repeated pregnancies [33]. It is crucial that adolescents understand the 
harmful effects of early marriage, know the legal age at marriage, and voice their demands to parents and society.

Congruent to other studies, we found that a higher percentage of girls showed lower self-efficacy scores compared to boys [34, 35]. Self-efficacy defines one's belief in his/her ability to perform the behaviors required to produce the desired outcome. Self-efficacy helps adolescents make decisions that affect their careers, health, lifestyle, and reproductive health, and control risk-taking behavior [36]. Adolescents who show higher self-efficacy are perceived to better voice their demands, have desired timing of their marriage, and are on track to the future goals [37]. Like other studies, a high prevalence of low selfefficacy in our study can be linked with low educational and socio-economic status (nearly two-thirds with below poverty line card) of the population and a higher representation from the marginalized classes of the society [38].

Unlike for general health problems, a low number of adolescents accessed health facilities for reproductive health issues in our study. Furthermore, girls visited facilities for reproductive health issues less often than boys. There is empirical evidence that young women seek treatment for genital infections less often than men, the reasons of which are shyness, financial constraints, and lack of awareness about services [39]. Studies have also highlighted the absence of healthcare providers, lack of confidentiality, poor quality, and unfriendly services at facilities as common reasons for adolescents not to visit health facilities for reproductive health problems, particularly government facilities [39].

Our findings show that more than $50 \%$ of both girls and boys wanted to marry late, but they were married off early in their society. The difference in their desirable and actual age at which they were married off is more than 2 years among $52 \%$ of adolescents. The recently concluded TAG survey reported that more than $70 \%$ of girls aspire to get married after 21 years of age (i.e., 3 years after the legal age of 18). More than three-fourths of girls wanted to do graduation before getting married [40]. Social norms in Indian society, particularly in rural areas, are against girls' education and support child marriage. Parents often want to marry off their daughters early as older brides are not accepted widely, delayed marriage may lead to premarital sex, which brings dishonor to the family, and they need to pay a higher dowry for an educated bride. Such norms coexist with norms that discourage women's employment and economic independence and support domestic violence [41].

Menstrual hygiene practices were similar among early as well as late adolescents in the present study. Cloths are commonly used as absorbents in rural areas compared to sanitary napkins in the urban areas [42]. Likewise, clothes were commonly used, followed by commercial pads in our study. A large proportion of girls reported problems during periods, such as excessive bleeding during periods, irregular periods, painful periods, pain in the lower abdomen, and missed periods in the present study. Such menstrual problems have been reported in other studies from India, with prevalence ranging from $64 \%$ to $80 \%$ [4345]. There is no convincing evidence on the factors associated with menstrual problems in adolescent girls, and studies have highlighted different predictors, such as delayed age at menarche, biological factors like high body mass index, and changing lifestyle patterns such as eating junk food and reducing 
physical activities, etc. [46-48]. Notably, menstrual problems have medical and social impacts on the life of adolescents, including the inability to perform household chores, sports activities, and school assignments, leading to school absenteeism and scolding by parents [49]. Inadequate access to safe water and sanitation may prevent effective menstrual hygiene management practices by girls. Like other studies, nearly $15 \%$ of girls did not have toilets at home [50]. Under the umbrella of the Clean Indian Campaign (Swachh Bharat Abhiyan), the government of India has been pushing states to promote the building of toilets in every household and eliminate open defecation. As a result of the campaign, the percentage of rural households with toilets increased from a meager $21 \%$ in 2012 to $56 \%$ by 2018 in Bihar. On the contrary, in Assam, more than $95 \%$ rural and $86 \%$ urban households have individual toilets $[51,52]$.

Illiteracy and early adolescence have conventionally been found to be associated with low reproductive health knowledge [53], and we concur with these findings. An increasing amount of research acknowledges the influence of religious beliefs and cultural practices on reproductive health knowledge and practices of women. Islamic norms, social control by parents, and social network could possibly act as barriers in acquiring sexuality education and accessing reproductive health services [54]. Despite such barriers, previous attempts by not-for-profit organizations have proved cornerstone in enhancing the reproductive health knowledge of adolescents in the state of Bihar. Furthermore, the studies highlighted that long-term effort is needed for difficult-to-change aspects of young people's reproductive health-child marriage and early pregnancy. Equally important is to engage with other key stakeholders, such as parents, school teachers, community leaders, and health systems for sustained change $[55,56]$.

\section{Limitations}

The following limitations should be considered during interpretation of the results. The study was purposively conducted among marginalized populations in the least developed states of India, Bihar and Assam. Hence, the findings do not represent the true scenario of Indian adolescents. Since the interviews were conducted at home in the presence of parents; as a result, responses to some of the questions, such as awareness about HIV/AIDS/Contraceptives, may have been underreported or not correctly reported. Lastly, recall bias might have occurred in some of the questions related to the experience of general health problems or reproductive health problems in the last 3-6 months.

\section{Conclusions}

We found inequalities in the reproductive health knowledge and practices of adolescents in the state of Bihar and Assam. Adolescent boys and girls in the early age group and with less educational status had comparatively low reproductive health knowledge and self-efficacy than their counterparts. We emphasize on the need of comprehensive (covering a broad range of reproductive health issues, such as child marriage, contraceptives, HIV/AIDS, menstrual hygiene, etc.), contextualized (relevant for adolescents in their areas), and customized (tailored for different cultures and religions through appropriate means) sexual and reproductive health education for adolescents. Keeping in mind, the 
experimentation phase of adolescence with increased indulgence in risk behaviours, the school- or community-based education programs should be designed, intervening from the early adolescence itself. The collective action of different stakeholders, including civil society organizations, government authorities, and local governing bodies, is required to uproot socio-cultural barriers that prevent such interventions in societies. Lastly, we underscore the dire need to work on these issues in the eastern states of India, like Bihar, that lag behind most other states in the health development index and prosperity.

\section{List Of Abbreviations}

GSES: General Self-Efficacy Scale

NFHS- National Family Health Survey

PPS: Probability Proportional to Size

PSU: Primary Sampling Unit

RTI: Reproductive Tract Infections

\section{Declarations}

\section{Ethics approval and consent to participate}

MAMTA Institutional Review Board (MIRB) granted ethical clearance for the study. We did not have issues while obtaining the consents as MAMTA has been working for the last 10 years in the states and has a good rapport with the community stakeholders and local government functionaries. Besides, due consent of parents and assent of adolescents were taken before the start of each interview.

\section{Consent for publication}

Not Applicable

\section{Availability of data and materials}

Due to the institutional policy, the authors could not provide the datasets along with the manuscript, but the same can be made available on a personal request.

\section{Competing interests}

The authors declare that the research was conducted in the absence of any commercial or financial relationships that could be construed as a potential conflict of interest.

\section{Funding}


The study was a part of an implementation project funded by ITC, India under Corporate Social Responsibility. The funder was not engaged in any component of the study.

\section{Authors' contributions}

Shantanu Sharma was involved in the formal analysis and writing of the original draft. Sonali Maheshwari and Jitesh Kuwatada conceptualized the study and reviewed the manuscript; Chandrashekhar contributed to the analysis and editing of the first draft of the manuscript and Sunil Mehra supervised the study and reviewed the final manuscript. All authors have read and agreed to the publication of this article.

\section{Acknowledgements}

We acknowledge the efforts of Ajay Singh and Rachna Patel in developing the research methodology and study tools, and performing first analysis of the data. Further, we extend our thanks to the district teams and field investigators who contributed their time and efforts in collecting the data.

\section{References}

1. Rose-Clarke K, Pradhan H, Rath S, Rath S, Samal S, Gagrai S, et al. Adolescent girls' health, nutrition and wellbeing in rural eastern India: a descriptive, cross-sectional community-based study. BMC Public Health. 2019;19.

2. Costello A. The time is right to invest in adolescents Geneva: World Health Organization; 2016 [Available from: https://www.who.int/mediacentre/commentaries/investing-in-adolescents/en/.

3. Arora SK, Shah D, Chaturvedi S, Gupta P. Defining and Measuring Vulnerability in Young People. Indian J Community Med. 2015;40(3):193-7.

4. United Nations Population Fund. Facing the facts: Adolescent girls and contraception. New York, United States; 2016.

5. Munakampe MN, Zulu JM, Michelo C. Contraception and abortion knowledge, attitudes and practices among adolescents from low and middle-income countries: a systematic review. BMC Health Serv Res 2018;18.

6. Chandra-Mouli V, Patel SV. Mapping the knowledge and understanding of menarche, menstrual hygiene and menstrual health among adolescent girls in low- and middle-income countries. Reprod Health. 2017;14.

7. Santelli JS, Song X, Garbers S, Sharma V, Viner RM. Global Trends in Adolescent Fertility, 1990-2012, in Relation to National Wealth, Income Inequalities, and Educational Expenditures. J Adolesc Health. 2017;60(2):161-8.

8. Kyilleh JM, Tabong PT, Konlaan BB. Adolescents' reproductive health knowledge, choices and factors affecting reproductive health choices: a qualitative study in the West Gonja District in Northern region, Ghana. BMC Int Health Hum Rights. 2018;18. 
9. Sheehan P, Sweeny K, Rasmussen B, Wils A, Friedman HS, Mahon J, et al. Building the foundations for sustainable development: a case for global investment in the capabilities of adolescents. Lancet. 2017;390(10104):1792-806.

10. Azzopardi PS, Hearps SJC, Francis KL, Kennedy EC, Mokdad AH, Kassebaum NJ, et al. Progress in adolescent health and wellbeing: tracking 12 headline indicators for 195 countries and territories, 1990-2016. Lancet. 2019;393(10176):1101-18.

11. Andrea J. Hoopes, Agarwal P, Bull S, Chandra-Mouli V. Measuring adolescent friendly health services in India: A scoping review of evaluations. Reprod Health. 2016;13.

12. Wadhwa R, Chaudhary N, Bisht N, Gupta A, Behera N, Verma A, et al. Improving adolescent health services across high priority districts in 6 states of India: Learnings from an integrated reproductive maternal newborn child and adolescent health project. 2018;43(5):6-11.

13. United Nations Population Fund. Ending Child Marriage: Progress and prospects. New York; 2014.

14. United Nations Population Fund. Adolescent pregnancy: A review of the evidence. New York; 2013.

15. Ministry of Health and Family Welfare. 10th Common Review Mission. New Delhi; 2016.

16. Nagata JM, Ferguson BJ, Ross DA. Research Priorities for Eight Areas of Adolescent Health in Lowand Middle-Income Countries. J Adol Health. 2016:1-11.

17. Hindin MJ, Christiansen CS, Ferguson BJ. Setting research priorities for adolescent sexual and reproductive health in low- and middle-income countries. Bull World Health Organ. 2013;91:10-8.

18. Bhan N, Rao KD, Kachwaha S. Health inequalities research in India: a review of trends and themes in the literature since the 1990s. Int J Equity Health 2016;15:166.

19. Mamilla S GS. Knowledge about menstrual hygiene, sexual health, and contraception in educated late adolescent age girls. J Family Med Prim Care 2019;8(2):610-3.

20. Schwarzer R, Jerusalem M. Generalized Self-Efficacy scale. A user's portfolio. Causal and control beliefs. NFER-Nelson; 1995.

21. Jain M, Jain S, Patil S, Bang A. A study on knowledge attitude and practice of contraception in school going children in Wardha district in central India. Int J Reprod Contracept Obstet Gynecol. 2014;3(4):903-8.

22. Renjhen P, Kumar A, Pattanshetty S, Sagir A, Samarasinghe CM. A study on knowledge, attitude and practice of contraception among college students in Sikkim, India. Journal of the Turkish German Gynecological Association. 2010;11(2):78-81.

23. Guzzo KB, Hayford SR. Adolescent Reproductive and Contraceptive Knowledge and Attitudes and Adult Contraceptive Behavior. Matern Child Health J. 2018;22(1):32-40.

24. Muthuraja M, Dhanes V. Assessment of knowledge among adolescents regarding HIV/AIDS in Chennai, Southern India. Int J Contemp Pediatr. 2015;2(4):263-7.

25. Verma UK, Nandan D, Shrotriya VP. A Comparative Study of Knowledge and Attitude Regarding HIV/AIDS among Male and Female Adolescents of Urban Slums of Agra. Ntl J Com-munity Med. 2016;7(2):78-81. 
26. Dhruvendra L, Onam G, Tanvir SK. To Study Knowledge Attitude and Practice Regarding HIV/AIDS among Adolescents. Ind J Youth Adol Health 2017;4(2):44-50.

27. Camlin CS, Ssemmondo E, Chamie G, Alison M. Ayadi El, Kwarisiima D, et al. Men "missing" from population-based HIV testing: insights from qualitative research. AIDS Care. 2013;28(Sup3):67-73.

28. International Institute of Population Sciences and ICF. National Family Health Survey (NFHS-4), 2015-16: India. Mumbai: IIPS; 2017.

29. Dogra A, Menia V, Pandita K. Knowledge, Attitude, and Practice Study of Adolescent Girls about Safe Sexual Practices. Int J Sci Stud. 2019;7(8):77-80.

30. Ahuja VK, Patnaik S, Gurchandandeep, Lugani Y, Sharma N, Goyal S, et al. Perceptions and preferences regarding sex and contraception, amongst adolescents. J Family Med Prim Care. 2019;8(10):3350-5.

31. Kansal S, Singh S, Kumar A. Awareness of legal and social issues related to reproductive health among adolescent girls in rural Varanasi. Indian J Public Health 2017;61:26-32.

32. Naidu SA, Vennam BSV, PKVS. Knowledge about reproductive health among adolescent high school girls (rural) in Karapa mandal, East Godavari district. Int J Res Health Sci 2014;2(2):543-6.

33. Maswikwa B, Richter L, Kaufman J, Nandi A. Minimum Marriage Age Laws and the Prevalence Of Child Marriage and Adolescent Birth: Evidence from Sub-Saharan Africa. International Perspectives on Sexual and Reproductive Health. 2015;41:58-68.

34. Revollo OE, Portela MJO. Self-efficacy, Agency and Empowerment During Adolescence and Young Adulthood in Ethiopia, India, Peru and Vietnam. 2019.

35. Santhya KG, Acharya R, Pandey N, Gupta AK, Rampal S, Singh SK, et al. Understanding the lives of adolescents and young adults (UDAYA) in Uttar Pradesh, India. New Delhi: Population Council.; 2017.

36. Lönnfjord V, Hagquist, C. The Psychometric Properties of the Swedish Version of the General SelfEfficacy Scale: A Rasch Analysis Based on Adolescent Data. Curr Psychol 2018;37:703-15.

37. Packer C, Ridgeway K, Lenzi R, González-Calvo L, Moon TD, Green AF, et al. Hope, Self-Efficacy, and Crushed Dreams: Exploring How Adolescent Girls' Future Aspirations Relate to Marriage and Childbearing in Rural Mozambiqu. Journal of Adolescent Research. 2020;35(5):579-604.

38. Sharma S, Akhtar F, Singh RK, Mehra S. Relationships between nutrition-related knowledge, attitude, and self-efficacy among adolescents: A community-based survey. J Family Med Prim Care. 2019;8:2012-6.

39. Sivakami M, Rai S. Health and Well-being of India's young people: Challenges and prospects. Shalini Bharat GS, editor. Singapore: Springer; 2019. 121-56 p.

40. Nandi Foundation. The Teen Age Girls Survey 2018. Mumbai, India; 2018.

41. Raj A, Salazar M, Jackson EC, Wyss N, McClendon KA, Khanna A, et al. Students and brides: a qualitative analysis of the relationship between girls' education and early marriage in Ethiopia and India. BMC Public Health 2019;19(1):19. 
42. Van Eijk AM, Sivakami M, Thakkar MB, Bauman A, Laserson KF, Coates S, Phillips-Howard PA. Menstrual hygiene management among adolescent girls in India: a systematic review and metaanalysis. BMJ open. 2016;6(3).

43. Omidvar S, Amiri FN, Bakhtiari A, Begum K. A study on menstruation of Indian adolescent girls in an urban area of South India. J Family Med Prim Care 2018;7(4):698-702.

44. Vinod Ramdasji Wasnik DD, Ajay Keshavrao Jawarkar. A study of the menstrual pattern and problems among rural school going adolescent girls of Amravati district of Maharashtra, India. International journal of research in medical sciences. 2015;3(5).

45. Varghese L, Prakash PJ, Viswanath L. A Study to Identify the Menstrual Problems and Related Practices among Adolescent Girls in Selected Highe Secondary School in Thiruvananthapuram, Kerala, India. Journal of South Asian Federation of Obstetrics and Gynaecology. 2019;11(1):13-6.

46. Lakkawar NJ, Jayavani RL, Nivedhana AP, Alaganandam P, Vanajakshi N. A study of menstrual disorders in medical students and its correlation with biological variables. Sch J App Med Sci 2014;2:3165-75.

47. Singh M, Rajoura OP, Honnakamble RA. Menstrual patterns and problems in association with body mass index among adolescent school girls. . J Family Med Prim Care. 2019;8(9):2855-8.

48. Sanctis VD, Rigon F, Bernasconi S, Bianchin L, Bona G, Bozzola M, et al. Age at Menarche and Menstrual Abnormalities in Adolescence: Does it Matter? The Evidence from a Large Survey among Italian Secondary Schoolgirls. The Indian Journal of Pediatrics. 2019;86.

49. Ravi R, Shah PB, Edward S, Gopal P, Sathiyasekaran BW. Social impact of menstrual problems among adolescent school girls in rural Tamil Nadu. International journal of adolescent medicine and health. 2017;30(5).

50. Choudhary N, Guptak MK. A comparative study of perception and practices regarding menstrual hygiene among adolescent girls in urban and rural areas of Jodhpur district, Rajasthan. J Family Med Prim Care 2019;8(3):875-80.

51. Ministry of Statistics and Programme Implementation. National Sample Survey 76th round. New Delhi: Government of India; 2018.

52. Ministry of Statistics and Programme Implementation. Swachhta Status in India;. New Delhi, India: Government of India; 2018.

53. Prata N, Weidert K. Adolescent Sexual and Reproductive Health. 2020.

54. Arousell J, Carlbom A. Culture and religious beliefs in relation to reproductive health. . Best practice \& research Clinical obstetrics \& gynaecology 2016;32:77-87.

55. Shinde S, Weiss HA, Varghese B, Khandeparkar P, Pereira B, Sharma A, et al. Promoting school climate and health outcomes with the SEHER multi-component secondary school intervention in Bihar, India: a cluster-randomised controlled trial. The Lancet 2018;392:2465-77.

56. Pandey N, Jejeebhoy S, Acharya R, Singh SK, Srinivas M. Effects of the PRACHAR project's reproductive health training programme for adolescents: Findings from a longitudinal study. New Delhi: Population Council; 2016. 


\section{Tables}

Table 1. Distribution of socio-demographic characteristics by gender of adolescents 


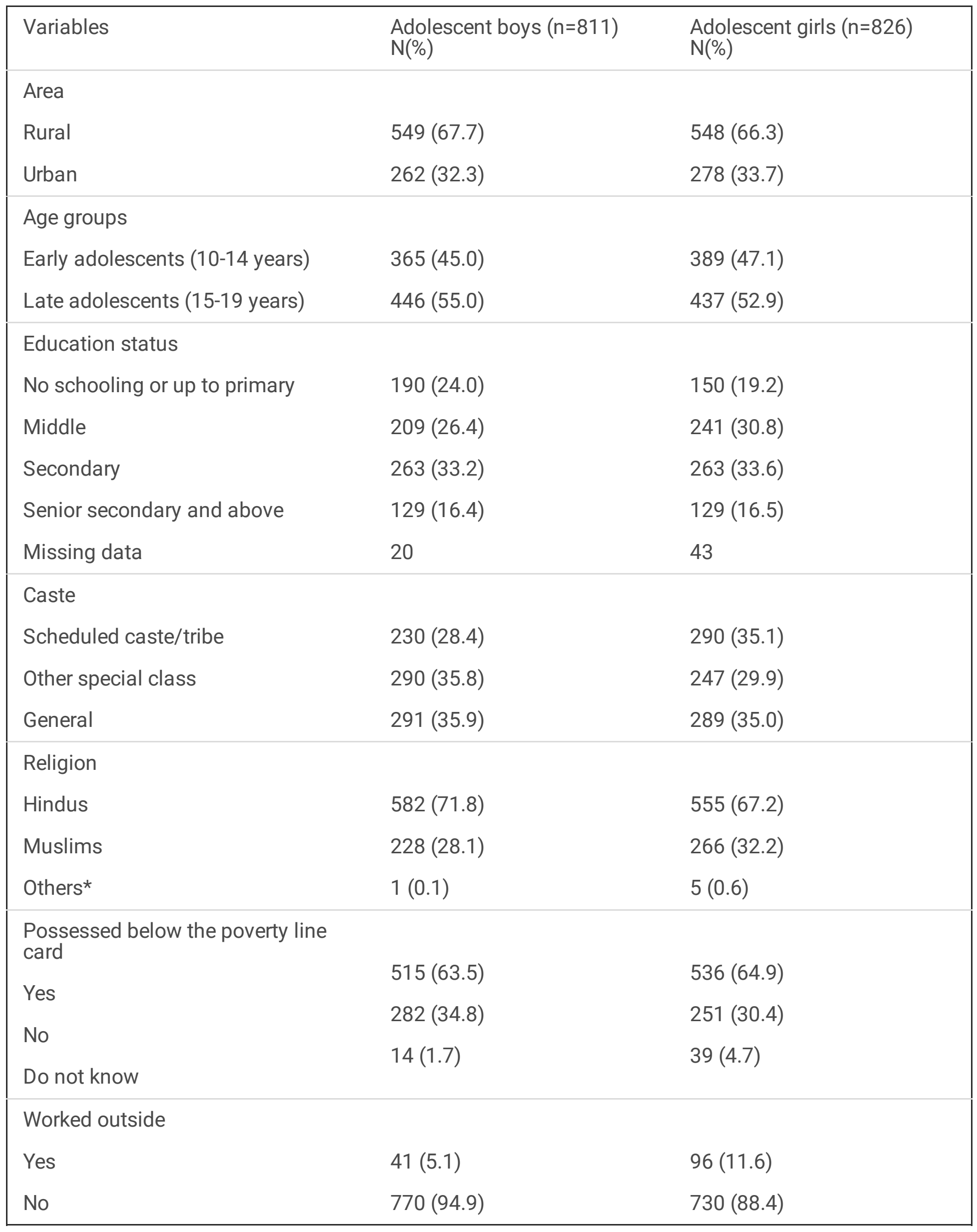


*Others included Sikhs, Christians, and Jains

Table 2. Distribution of the prevalence of knowledge and practices of reproductive health between adolescent boys and girls 


\begin{tabular}{|c|c|c|}
\hline Variables & $\begin{array}{l}\text { Adolescent boys } \\
(n=811) N(\%)\end{array}$ & $\begin{array}{l}\text { Adolescent girls } \\
(n=826) \mathrm{N}(\%)\end{array}$ \\
\hline \multicolumn{3}{|c|}{ Awareness score of contraceptives } \\
\hline Low (0-3) & $726(89.5)$ & $768(93.0)$ \\
\hline Medium (4-6) & $75(9.2)$ & $52(6.3)$ \\
\hline High (7-9) & $10(1.2)$ & $6(0.7)$ \\
\hline \multicolumn{3}{|l|}{ Heard of AIDS } \\
\hline Yes & $289(35.6)$ & $202(24.5)$ \\
\hline No & $522(64.0)$ & $624(75.5)$ \\
\hline \multicolumn{3}{|l|}{ Heard of HIV } \\
\hline Yes & $205(25.3)$ & $163(19.7)$ \\
\hline No & $606(74.7)$ & $663(80.3)$ \\
\hline Knowledge score of HIV/AIDS* & $n=205$ & $n=163$ \\
\hline Low score (0-2) & $56(27.3)$ & $79(48.5)$ \\
\hline Medium score (3-4) & $91(44.4)$ & $65(39.9)$ \\
\hline High score (5-6) & $58(28.3)$ & $19(11.6)$ \\
\hline \multicolumn{3}{|c|}{ Aware of legal age at marriage of girls } \\
\hline Know & $588(72.5)$ & $624(75.5)$ \\
\hline Don't know & $223(27.5)$ & $202(24.5)$ \\
\hline \multicolumn{3}{|c|}{ Aware of legal age at marriage of boys } \\
\hline \multicolumn{3}{|l|}{ Know } \\
\hline \multirow[t]{2}{*}{ Don't know } & $553(68.2)$ & $568(68.8)$ \\
\hline & $258(31.8)$ & $258(31.2)$ \\
\hline \multicolumn{3}{|l|}{ Self-efficacy scores } \\
\hline Low (12-31) & $185(22.8)$ & $363(43.9)$ \\
\hline Middle (32-39) & $326(40.2)$ & $232(28.1)$ \\
\hline High (40-48) & $300(37.0)$ & $231(28.0)$ \\
\hline \multicolumn{3}{|c|}{ Had any general health problem in the past 6-months? } \\
\hline \multicolumn{3}{|l|}{ Yes } \\
\hline No & $148(18.2)$ & $281(34.0)$ \\
\hline
\end{tabular}




\begin{tabular}{|c|c|c|}
\hline & $663(81.8)$ & $545(66.0)$ \\
\hline Access to services for health problems & $n=148$ & $n=281$ \\
\hline \multicolumn{3}{|l|}{ Home remedy/no action } \\
\hline Health facility (public/private) & $29(19.6)$ & $87(31.0)$ \\
\hline \multirow[t]{2}{*}{ Quack/traditional healer } & $116(78.4)$ & $161(57.3)$ \\
\hline & $3(2.0)$ & $33(11.7)$ \\
\hline \multicolumn{3}{|c|}{$\begin{array}{l}\text { Had reproductive tract infections or diseases in the past } 12 \text { - } \\
\text { months? }\end{array}$} \\
\hline \multicolumn{3}{|l|}{ Yes } \\
\hline \multirow{2}{*}{$\begin{array}{l}\text { No } \\
\text { Do not know }\end{array}$} & $29(0.1)$ & $47(0.9)$ \\
\hline & $681(87.6)$ & $430(54.4)$ \\
\hline \multirow{2}{*}{ Missing } & $68(8.7)$ & $313(39.6)$ \\
\hline & 33 & 36 \\
\hline \multicolumn{3}{|c|}{$\begin{array}{l}\text { Had symptoms suggestive of reproductive tract infection or } \\
\text { disease (self-reported) in the last 3-months }\end{array}$} \\
\hline \multicolumn{3}{|l|}{ Yes } \\
\hline \multicolumn{3}{|l|}{ No } \\
\hline \multirow{2}{*}{ Don't remember } & & \\
\hline & $102(90.2)$ & $481(60.9)$ \\
\hline \multirow{2}{*}{ Missing } & $6(0.8)$ & $130(16.4)$ \\
\hline & 33 & 36 \\
\hline Access to services for reproductive health problems & $\mathrm{n}=70$ & $n=179$ \\
\hline \multicolumn{3}{|l|}{ Home remedy } \\
\hline \multirow[t]{2}{*}{ Health facility (public/private) } & $16(22.8)$ & $26(14.5)$ \\
\hline & $22(31.4)$ & $60(33.5)$ \\
\hline Quacks & $3(4.3)$ & $7(4.0)$ \\
\hline No treatment & $29(41.4)$ & $86(48.0)$ \\
\hline \multicolumn{3}{|c|}{$\begin{array}{l}\text { Difference between the desire \& societal pressure in the age } \\
\text { to marry } \mathbb{}\end{array}$} \\
\hline \multicolumn{2}{|l|}{$\leq 1$ year } & $384(47.6)$ \\
\hline 2-5 years & 187 (23.6) & $230(28.5)$ \\
\hline$>5$ years & $213(26.9)$ & $193(23.9)$ \\
\hline Missing & & \\
\hline
\end{tabular}


Perception of early marriage of boys in area§

Yes

No

118 (17.6)

$134(19.6)$

Missing

$554(82.4)$

$549(80.4)$

139

143

Perception of early marriage of girls in area†

Yes

$127(18.7)$

89 (13.2)

No

$584(86.8)$

Missing

133

153

Aware of any government scheme or policy to stop child marriage

Yes

No

$23(2.8)$

$788(97.2)$
$149(18.0)$

$677(82.0)$

WIt is the difference between the age at which adolescents wanted to marry and age at which adolescents were married off in their society. So higher difference indicate that adolescents were married off much early in their area despite their desire to marry late

SIt is based on the number of adolescents who perceived that boys were married off early before the legal age in their area

tlt is based on the number of adolescents who perceived that girls were married off early before the legal age in their area

Table 3. Menstrual hygiene practices among girls between early and late adolescent groups 


\begin{tabular}{|lll|}
\hline Variables & $\begin{array}{l}\text { Early adolescent }(\mathrm{n}=223) \\
\mathrm{N}(\%)\end{array}$ & $\begin{array}{l}\text { Late adolescent girls }(\mathrm{n}=412) \\
\mathrm{N}(\%)\end{array}$ \\
$\begin{array}{l}\text { Mean }(\mathrm{SD}) \text { age of menarche } \\
\text { (years) }\end{array}$ & $12.1(1.1)$ & $13.1(1.1)$ \\
\hline $\begin{array}{l}\text { Type of sanitary pad used } \\
\text { Clothes }\end{array}$ & $107(48.0)$ & $169(41.0)$ \\
Local napkin & $17(7.6)$ & $56(13.6)$ \\
Commercial sanitary napkin & $96(43.0)$ & $185(44.9)$ \\
Other material like paper or & $3(1.3)$ & $2(0.5)$ \\
leaves & $\mathrm{n}=107$ & $\mathrm{n}=169$ \\
Cleaning of the cloth & $49(45.8)$ & $65(38.5)$ \\
Wash with soap & $53(49.5)$ & $93(55.0)$ \\
Do not reuse & $5(4.7)$ & $11(6.6)$ \\
Others & & \\
\hline Periods-related problems* & $146(65.4)$ & $313(76.0)$ \\
Yes & $77(34.6)$ & $99(24.0)$ \\
No & $182(81.6)$ & $362(87.8)$ \\
Toilet at home & $41(18.4)$ & $50(12.1)$ \\
Yes & & \\
No & & \\
\hline
\end{tabular}

Abbreviation: SD: Standard Deviation

9Others include did not wash it with soap, or did not wash it with anything, and sun drying only *girls were asked if they had problems like excessive bleeding during periods, irregular periods, painful periods, pain in lower abdomen, missed periods.

The figure illustrates the study settings where Munger district in Bihar and Darang district in Assam were selected. Forty-five urban wards in Munger district and 3 Gram Panchayats (local governing bodies) were chosen randomly for sampling. Likewise, 2 Gram Panchayats (local governing bodies) in the Darang district were chosen.

Note: Frontline workers included accredited social health activists and auxiliary nurse midwives 
All figures are in percentages

The figure depicts the distribution of source of information for contraceptives among boys and girls. Most commonly advertisements and friends were the sources. Nearly $21 \%$ of boys approached quacks and an equal percentage visited health facilities for information about contraceptives.

Table 4a. Percent distribution of three clusters according to selected items of reproductive health knowledge and self-efficacy among boys $(n=811)$

\begin{tabular}{|llll|}
\hline $\begin{array}{l}\text { Selected reproductive } \\
\text { health items }\end{array}$ & $\begin{array}{l}\text { High knowledge and } \\
\text { self-efficacy cluster } \\
\text { Response (\%) }\end{array}$ & $\begin{array}{l}\text { Medium knowledge and } \\
\text { self-efficacy cluster } \\
\text { Response (\%) }\end{array}$ & $\begin{array}{l}\text { Low knowledge and } \\
\text { self-efficacy cluster } \\
\text { Response (\%) }\end{array}$ \\
\hline Cluster size (\%) & 31.8 & 37.1 & 31.1 \\
\hline $\begin{array}{l}\text { Aware about boys' } \\
\text { legal age at marriage }\end{array}$ & Know (96.9) & Know (100) & Don't know (99.2) \\
\hline $\begin{array}{l}\text { Aware about legal age } \\
\text { at marriage of girls }\end{array}$ & Know (100) & Know (87) & Don't know (88.5) \\
\hline Heard of AIDS & Yes (98.1) & No (100) & No (93.3) \\
\hline Heard of HIV & Yes (72.9) & No (100) & Low (52.0) \\
\hline Self-efficacy scores & High (49.6) & Medium (52.7) & Low (97.6) \\
\hline $\begin{array}{l}\text { Contraceptive } \\
\text { knowledge scores }\end{array}$ & Low (83.7) & Low (87.7) & \\
\hline
\end{tabular}

Contribution of each item to the clustering solution as reported from the Two-Step cluster analysis. This shows the index of relative importance of each reproductive health item as identified by the Two-Step cluster analysis.

Table 4b. Percent distribution of three clusters according to selected items of reproductive health knowledge and self-efficacy among girls $(n=826)$ 


\begin{tabular}{|c|c|c|c|}
\hline $\begin{array}{l}\text { Selected reproductive } \\
\text { health items }\end{array}$ & $\begin{array}{l}\text { High knowledge and } \\
\text { low self-efficacy } \\
\text { cluster } \\
\text { Response (\%) }\end{array}$ & $\begin{array}{l}\text { Medium knowledge and } \\
\text { low self-efficacy cluster } \\
\text { Response (\%) }\end{array}$ & $\begin{array}{l}\text { Low knowledge and } \\
\text { low self-efficacy } \\
\text { cluster } \\
\text { Response (\%) }\end{array}$ \\
\hline Cluster size (\%) & 31.8 & 46.9 & 21.3 \\
\hline $\begin{array}{l}\text { Aware about girls' } \\
\text { legal age at marriage }\end{array}$ & Know (90.1) & Know (100) & Don't know (100) \\
\hline Heard of AIDS & Yes (76.8) & No (100) & No (100) \\
\hline $\begin{array}{l}\text { Aware about legal } \\
\text { age at marriage of } \\
\text { boys }\end{array}$ & Know (68.4) & Know (100) & Don't Know (99.4) \\
\hline Heard of HIV & Yes (62.0) & No (100) & No (100) \\
\hline $\begin{array}{l}\text { Contraceptive } \\
\text { knowledge scores }\end{array}$ & Low (79.8) & Low (100) & Low (97.2) \\
\hline Self-efficacy scores & Low (41.1) & Low (37.7) & Low (61.9) \\
\hline
\end{tabular}

Contribution of each item to the clustering solution as reported from the Two-Step cluster analysis. This shows the index of relative importance of each reproductive health item as identified by the Two-Step cluster analysis.

Table 5a. Multinomial logistic regression analysis showing results of unadjusted and adjusted odds ratio of the high knowledge and self-efficacy cluster versus low knowledge and self-efficacy cluster with respect to selected background characteristics among boys $(n=811)$ 


\begin{tabular}{|c|c|c|c|c|}
\hline \multirow[t]{2}{*}{ Variables } & $\begin{array}{l}\text { Better-informed } \\
\text { cluster* }\end{array}$ & \multirow[t]{2}{*}{$\begin{array}{l}\mathrm{p} \\
\text { value }\end{array}$} & $\begin{array}{l}\text { High knowledge and self- } \\
\text { efficacy cluster * }\end{array}$ & \multirow[t]{2}{*}{$\begin{array}{l}\mathrm{p} \\
\text { value }\end{array}$} \\
\hline & $\begin{array}{l}\text { Unadjusted odds } \\
\text { ratio }(95 \% \mathrm{Cl})\end{array}$ & & $\begin{array}{l}\text { Adjusted odds ratio (95\% } \\
\mathrm{Cl} \text { ) }\end{array}$ & \\
\hline \multicolumn{5}{|l|}{ Area } \\
\hline Rural & $0.827(0.566-1.208)$ & 0.326 & 1.016 (0.617-1.674) & 0.951 \\
\hline Urban & Reference & & Reference & \\
\hline \multicolumn{5}{|l|}{ Age groups } \\
\hline $\begin{array}{l}\text { Early adolescents (10-14 } \\
\text { years) }\end{array}$ & $0.050(0.031-0.080)$ & $<0.001$ & $0.260(0.141-0.480)$ & $<0.001$ \\
\hline $\begin{array}{l}\text { Late adolescents (15-19 } \\
\text { years) }\end{array}$ & Reference & & Reference & \\
\hline \multicolumn{5}{|l|}{ Education status } \\
\hline Up to primary & $0.003(0.001-0.010)$ & $<0.001$ & $0.010(0.003-0.036)$ & $<0.001$ \\
\hline Middle class & $0.019(0.007-0.052)$ & $<0.001$ & $0.044(0.015-0.127)$ & $<0.001$ \\
\hline Secondary class & $0.177(0.067-0.466)$ & $<0.001$ & $0.213(0.079-0.570)$ & 0.002 \\
\hline $\begin{array}{l}\text { Senior secondary class } \\
\text { and above }\end{array}$ & Reference & & Reference & \\
\hline \multicolumn{5}{|l|}{ Religion } \\
\hline Hindu & $3.829(2.544-5.762)$ & $<0.001$ & $1.954(0.932-4.099)$ & 0.076 \\
\hline Others & 2.583 & & 0.546 & - \\
\hline Muslim & Reference & & Reference & \\
\hline \multicolumn{5}{|l|}{ Social caste } \\
\hline Scheduled caste/tribe & $2.041(1.300-3.202)$ & 0.002 & $0.931(0.447-1.936)$ & 0.848 \\
\hline Other special class & $3.583(2.342-5.482)$ & $<0.001$ & $1.340(0.640-2.803)$ & 0.438 \\
\hline General & Reference & & Reference & \\
\hline \multicolumn{5}{|l|}{$\begin{array}{l}\text { Possess below the } \\
\text { poverty line card }\end{array}$} \\
\hline Yes & $0.571(0.393-0.830)$ & 0.003 & $0.740(0.457-1.199)$ & 0.107 \\
\hline \multirow{2}{*}{$\begin{array}{l}\text { Don't know } \\
\text { No }\end{array}$} & $1.601(0.400-6.405)$ & 0.506 & $4.828(0.713-32.67)$ & \\
\hline & Reference & & Reference & \\
\hline
\end{tabular}




\begin{tabular}{|c|c|c|c|}
\hline Yes & $0.975(0.453-2.090)$ & 0.949 & $1.083(0.401-2.927)$ \\
\hline No & Reference & & Reference \\
\hline
\end{tabular}

Abbreviations: Cl: Confidence interval; $p$ value $<0.05$ was considered statistically significant

*Cluster 3 (Low knowledge and self-efficacy) was the reference category

Table 5b. Multinomial logistic regression analysis showing results of unadjusted and adjusted odds ratio of the high knowledge and self-efficacy cluster versus low knowledge and self-efficacy cluster with respect to selected background characteristics among girls $(n=826)$ 


\section{Variables}

High knowledge and low self-efficacy cluster*

p

Unadjusted odds ratio (95\%

$\mathrm{Cl})$

value

High knowledge and low

self-efficacy cluster *

p

Adjusted odds ratio (95\%

$\mathrm{Cl})$

Area

Rural

$0.495(0.323-0.758)$

Reference

0.001

$0.753(0.437-1.298)$

0.308

Urban

Age groups

Early adolescents

(10-14 years)

$0.138(0.089-0.213)$

$<0.001$

Reference
Late adolescents

(15-19 years)

Education status

Up to primary

Middle class

Secondary class

Senior secondary

class and above

Religion

Hindu

Others

Muslim

Social caste

Scheduled

caste/tribe

Other special class

General
$<0.001 \quad 0.013(0.003-0.061)$

$<0.001 \quad 0.055(0.012-0.255)$

$0.039 \quad 0.280(0.061-1.285)$

Reference
Reference

$0.008(0.002-0.033)$

0.029 (0.007-0.126)

0.206 (0.046-0.923)

Reference
Reference

$<0.001$

$<0.001$

0.102

$\begin{array}{lll}<.001 & 0.834(0.402-1.730) & 0.625\end{array}$

0.320

$3.187(0.325-31.278)$

Reference

Reference

$<0.001 \quad 3.204(1.401-7.326)$

0.006

$<0.001 \quad 2.135(0.965-4.723)$

0.061

Reference

Possess below the

poverty line card

Yes

Don't know

$1.075(0.715-1.616)$

0.730

$0.964(0.575-1.616)$

0.890

No

\section{$2.143(0.557-8.249)$}

Reference
0.268

$2.729(0.608-12.255)$

0.190

Work outside 


\begin{tabular}{|c|c|c|c|}
\hline Yes & $1.697(0.967-2.978)$ & 0.065 & $2.506(1.191-5.276)$ \\
\hline No & Reference & & Reference \\
\hline
\end{tabular}

Abbreviations: Cl: Confidence interval; $p$ value $<0.05$ was considered statistically significant

*Cluster 3 (Low knowledge and low self-efficacy) was the reference category

\section{Figures}

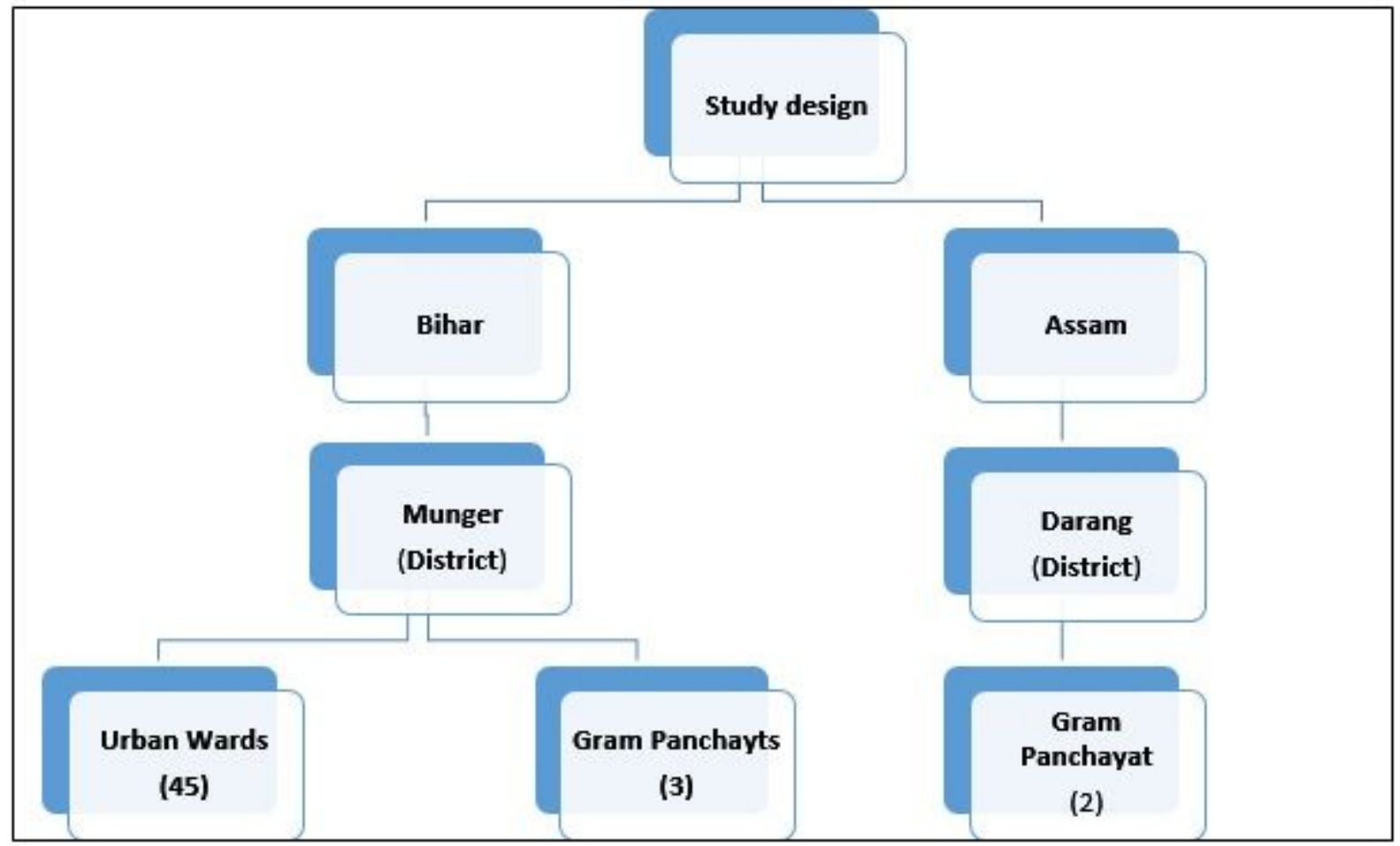

Figure 1

Study settings for the community-based cross-sectional survey 


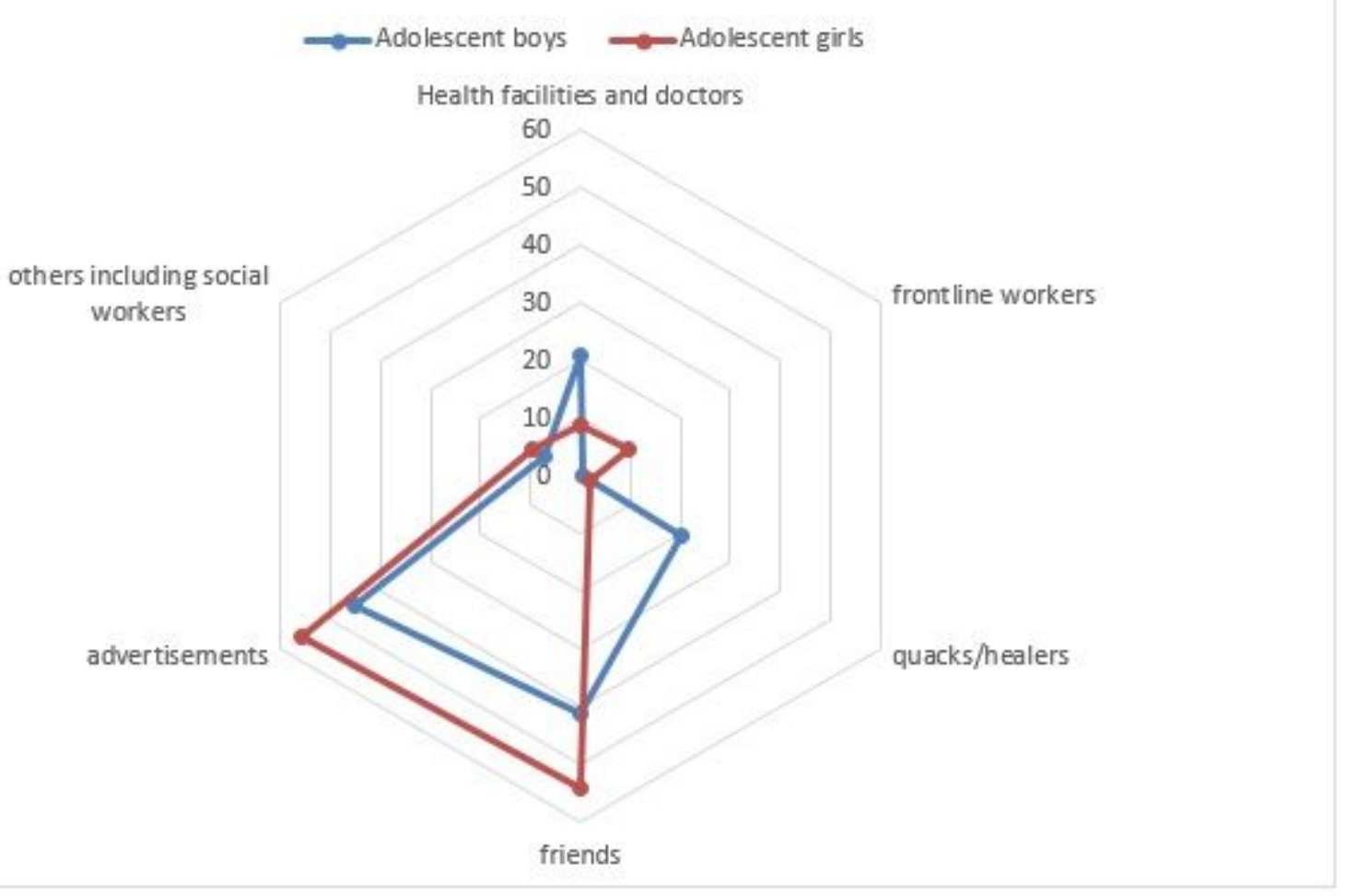

\section{Figure 2}

Sources of Information about contraceptives among boys and girls

a

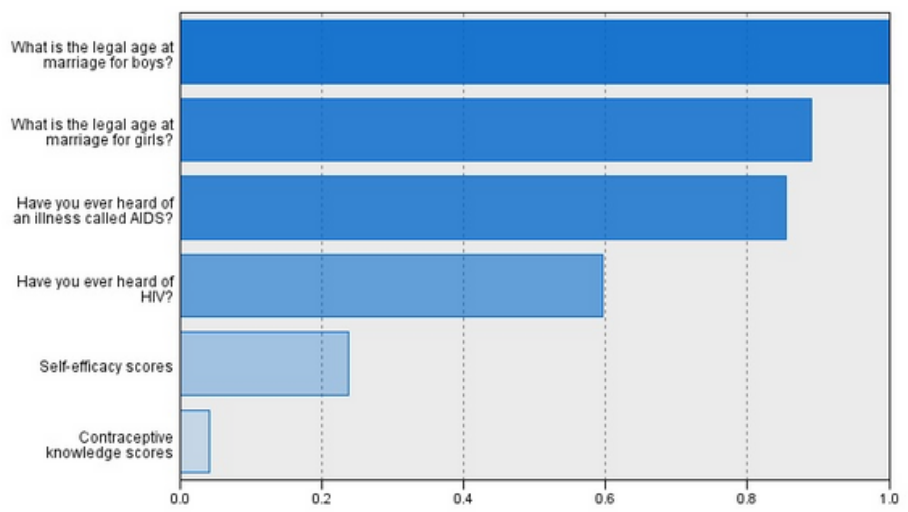

Least Important

Predictor Importance b

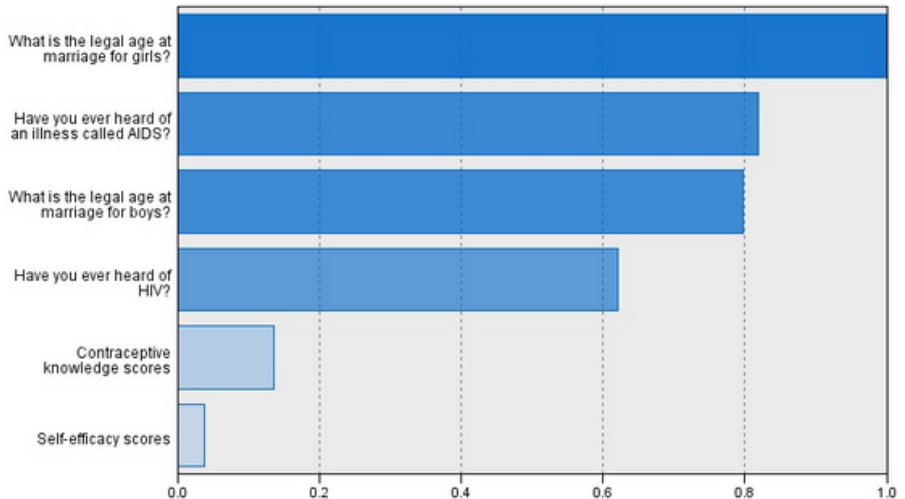

Least Important
Predictor Importance

Most Important

\section{Figure 3}

a. Predictor importance of the selected reproductive health knowledge and self-efficacy items among boys $(n=811)$ b. Predictor importance of the selected reproductive health knowledge and self-efficacy items among girls $(n=826)$ 